\title{
Estudo da redução de espessura de suporte metálico em pastilhas de freio automotivo
}

\author{
Study of backplate thickness reduction in automotive brake pads
}

\author{
Miguel Henrique Seimetz ${ }^{1} \quad$ Marcos Alexandre Luciano $^{2} \quad$ Carlos Alberto Costa $^{2}$
}

Recibido 8 de agosto de 2013, aceptado 23 de mayo de 2014

Received: August 8, $2013 \quad$ Accepted: May 23, 2014

\begin{abstract}
RESUMO
Os sistemas de freio são elementos críticos tanto para a segurança como para o desempenho do veículo, sendo que os do tipo a disco são amplamente usados em veículos leves por serem compactos e apresentarem boa dissipação de calor. Um dos componentes desse sistema é a pastilha de freio que possui um suporte metálico para fixar o material de atrito e que possui como função a distribuição da força de atuação, proporcionando contato uniforme sobre o disco de freio evitando deformações significativas do conjunto suporte metálico e material de atrito. Este artigo apresenta um estudo sobre a avaliação da espessura mínima do suporte metálico para sistemas de frenagem de veículos leves. Os principais parâmetros estudados estão associados ao torque e a força de frenagem e à temperatura de trabalho. O estudo do sistema foi validado por meio de ensaios em dinamômetro em condições de frenagens severas e ensaios de tração e micro dureza para o material do suporte metálico. Os resultados permitiram uma redução da espessura do suporte metálico de 5 para $4 \mathrm{~mm}$, atendendo as especificações mecânicas e térmicas associadas ao sistema de freio.
\end{abstract}

Palavras-chave: Desempenho de frenagem, espessura de suporte metálico, racionalização de custos.

\begin{abstract}
Brake system is a critical component for vehicle safety and performance. One type of brake system widely used in passenger cars is disc brake system due to its compactness and efficient heat dissipation. In this system brake pads play a key function, distributing the hydraulic force by the uniform contact with the brake disk with no deformations. Brake pads are composed of a support metallic backplate, where friction material is adhered. This work presents a study to evaluate the minimum acceptable backplate thickness, considering passenger vehicles braking performance and requirements. The main parameters evaluated on this work were associated with braking torque and force and working temperature. These parameters were validated based on dynamometer tests under severe braking conditions together with tensile and micro hardness tests. Results showed that a reduction up to $1 \mathrm{~mm}$ in backplate thickness is possible, complying with all mechanical and thermal specifications required for braking systems.
\end{abstract}

Keywords: Brake performance, backplate thickness, cost reduction.

\section{INTRODUÇÃO}

O sistema de freio é responsável pela redução da velocidade ou por cessar totalmente o movimento de um veículo, além de mantê-lo estacionado em rampas. Ao projetar um sistema de frenagem devem ser analisados aspectos como segurança, eficiência e durabilidade [1]. Os sistemas de freio a

1 Fras-le SA - Rodovia RS 122 km 66 N 10.945. Caxias do Sul, RS, Brasil. CEP 95115-550.

E-mail: miguel.seimetz@fras-le.com

2 Universidade de Caxias do Sul. Rua Francisco Getulio Vargas No 1.130. Caxias do Sul, RS, Brasil. CEP 95110-680.

E-mail: marcos.luciano@ucs.br, cacosta@ucs.br 
disco têm resistência superior ao desgaste e são de manutenção mais fácil, principalmente em função de sua geometria, quando comparados aos sistemas de freio a tambor [2].

O componente responsável por atritar com o disco para criar força contrária ao movimento é a pastilha de freio [3], que é composta por duas partes principais: uma feita de aço, chamada de suporte metálico e a outra por um material composto por fibras, partículas abrasivas, modificadores orgânicos, cargas minerais, lubrificantes e ligantes, denominada guarnição de freio. A guarnição é produzida por conformação a quente sobre o suporte metálico, e a sua função é garantir o atrito necessário para a frenagem do veículo [1].

Ao suporte metálico cabe a distribuição da força vinda do pistão para a superfície da pastilha, proporcionando contato uniforme sobre o disco de freio. Sua espessura deve ser capaz de suportar a força máxima do pistão sem que ocorra deformação significativa que comprometa o desempenho do produto [4]. Considerando o mercado brasileiro, o suporte metálico é um item de custo elevado em relação ao conjunto pastilha de freio, motivando esforços para a racionalização do seu custo em relação ao produto final.

Ao longo do ciclo de vida de um produto é comum a revisão do seu projeto buscando adequar o produto a novas exigências da empresa ou dos clientes. Este trabalho apresenta o design review do suporte metálico de uma pastilha de freio aplicada em sistemas de frenagem a disco de veículos leves.

O escopo do artigo está na redução da espessura do suporte metálico, garantindo a manutenção do desempenho e segurança de frenagem para o veículo. Foram propostas 8 etapas a serem seguidas com o objetivo de avaliar os principais parâmetros que influenciam a determinação da espessura do suporte metálico. O estudo foi realizado com base na regulamentação europeia UN/ECE 13 ou diretiva 71/320/EEC nas categorias M1 e N1, sendo os veículos classificados com peso bruto total de até 3,5 toneladas e com capacidade de transporte de até oito passageiros.

Inicialmente são apresentados os conceitos teóricos sobre as forças existentes na dinâmica da frenagem e a influência da temperatura no desempenho do sistema de freio. Na sequência são apresentadas as etapas do procedimento experimental e o ambiente onde esse foi realizado. Posteriormente os resultados experimentais e os teóricos são confrontados, gerando-se, a partir daí, as considerações finais.

\section{FRENAGEM VEICULAR: FORÇAS E TEMPERATURA}

\section{Forças atuantes na frenagem}

Durante a frenagem de um veículo, além da força gerada pelo sistema de freio, outras forças resistivas ao movimento também contribuem, quais sejam: rolamento, aerodinâmica, aclive ou declive que decorre da ação da gravidade sobre o veículo ao se deslocar em pavimentos inclinados e a inércia das partes rotativas [5]. A Figura 1 apresenta as principais forças que atuam no veículo sob frenagem num pavimento plano horizontal. Todas as forças que se opõem ao movimento do veículo, descritas anteriormente, podem ser denominadas comumente de forças de frenagem $\left(\mathrm{F}_{1}\right.$ e $\left.\mathrm{F}_{2}\right)$.

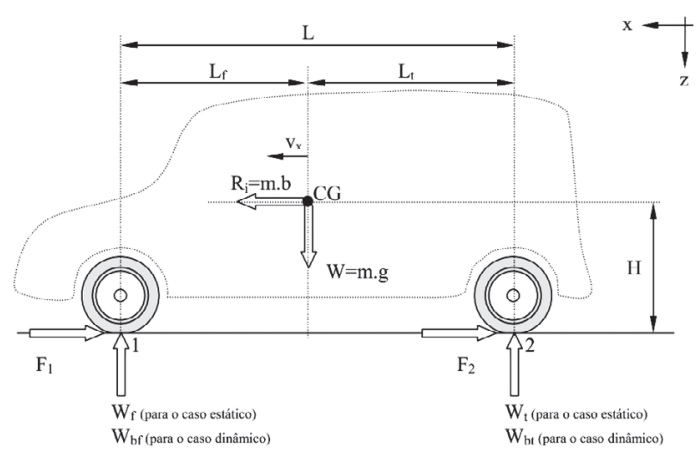

Figura 1. Sistema de forças atuantes em uma frenagem [6].

Onde:

$\mathrm{R}_{\mathrm{i}}$ : resultante de inércia do movimento acelerado de translação $(\mathrm{N})$;

$\mathrm{m}$ : massa total do veículo $(\mathrm{kg})$;

b: aceleração $\left(\mathrm{m} / \mathrm{s}^{2}\right)$;

$\mathrm{g}$ : aceleração da gravidade $\left(\mathrm{m} / \mathrm{s}^{2}\right)$;

$\mathrm{W}$ : força peso $(\mathrm{N})$;

$\mathrm{W}_{\mathrm{d}}$ : peso estático sobre o eixo dianteiro $(\mathrm{N})$;

$\mathrm{W}_{\mathrm{bd}}$ : peso dinâmico sobre o eixo dianteiro $(\mathrm{N})$;

$\mathrm{W}_{\mathrm{t}}$ : peso estático sobre o eixo traseiro $(\mathrm{N})$;

$\mathrm{W}_{\mathrm{bt}}$ : o peso dinâmico sobre o eixo traseiro $(\mathrm{N})$;

$\mathrm{F}_{1}$ : soma das forças de resistência impostas pelo solo à roda do eixo dianteiro $(\mathrm{N})$; 
$\mathrm{F}_{2}$ : soma das forças de resistência impostas pelo solo à roda do eixo traseiro $(\mathrm{N})$;

CG: centro de gravidade;

H: altura do CG em relação ao solo (mm);

L: distância entre eixos (mm);

$\mathrm{L}_{\mathrm{f}}$ : distancia do $\mathrm{CG}$ ao eixo dianteiro $(\mathrm{mm})$;

$\mathrm{L}_{\mathrm{t}}$ : distancia do $\mathrm{CG}$ ao eixo traseiro $(\mathrm{mm})$.

As forças resistivas ao movimento, não decorrentes do uso do freio, representam aproximadamente $1 \%$ da carga estática horizontal do eixo, caso esse não proporcione a tração do veículo, e 1,5\% da carga estática horizontal do eixo, caso esse proporcione a tração do veículo, conforme Norma ABNT NBR 14353 [7]. Desta forma, pode-se admitir que toda a força de frenagem é oriunda da força aplicada pelo sistema de freio.

As forças normais dinâmicas $\left(\mathrm{W}_{\mathrm{bd}}\right)$ e $\left(\mathrm{W}_{\mathrm{bt}}\right)$ devido à força de frenagem diferem das forças normais estáticas $\left(\mathrm{W}_{\mathrm{d}}\right)$ e $\left(\mathrm{W}_{\mathrm{t}}\right)$ devido ao efeito denominado transferência dinâmica de carga, que é diretamente dependente da desaceleração do veículo e da altura do centro de gravidade [6]. A transferência de carga alivia o peso sobre o eixo traseiro e aumenta o peso sobre o eixo dianteiro, quando o veículo se desloca à frente e freia. Admitindo uma condição ótima de frenagem [8], a equação (1) considera que a força de frenagem atuante no veículo é:

$$
F_{1}+F_{2} \approx F_{d}+F_{t}=\mu_{H F_{d}} \cdot W_{b d}+\mu_{H F_{t}} \cdot W_{b t}=m \cdot b(1)
$$

\section{Onde:}

$F_{d}$ : força de frenagem nos pneus dianteiros $(\mathrm{N})$; $\mathrm{F}_{\mathrm{t}}$ : força de frenagem nos pneus traseiros $(\mathrm{N})$; $\mu_{\mathrm{HFd}}$ : coeficiente de atrito com o solo nos pneus dianteiros;

$\mu_{\mathrm{HFt}}$ : coeficiente de atrito com o solo nos pneus traseiros.

A curva de distribuição de frenagem mostrada na Figura 2 ilustra nas ordenadas a razão entre a força de frenagem do eixo traseiro $\left(F_{t}\right)$ e o peso do veículo $(W)$ e, nas abscissas, a razão entre a força de frenagem do eixo dianteiro $\left(F_{d}\right)$ e o peso do veículo (W) [9-10]. As linhas inclinadas que partem do eixo das ordenadas para a direita são linhas de isoaderência para o eixo traseiro (4). Analogamente, as que partem das abscissas para cima são linhas de isoaderência para o eixo dianteiro (3). No cruzamento das linhas de isoaderência encontram-se os pontos que irão formar o lugar geométrico da distribuição ideal de frenagem (1).

A reta inclinada que parte da origem é a linha da distribuição instalada (2). As retas inclinadas a $45^{\circ}, \mathrm{z}=$ const, que partem da origem e crescem em diagonal para o canto direito superior são linhas de desaceleração constante. $\mathrm{O}$ cruzamento da curva da distribuição ideal com a linha da distribuição instalada determina o ponto conhecido como aderência crítica $\left(Z_{\text {KRIT }}\right)$ e a reta de desaceleração que por ali passa representa a máxima desaceleração que o sistema de freios pode proporcionar ao veículo sem que haja travamento do eixo traseiro antes do dianteiro [11-12].

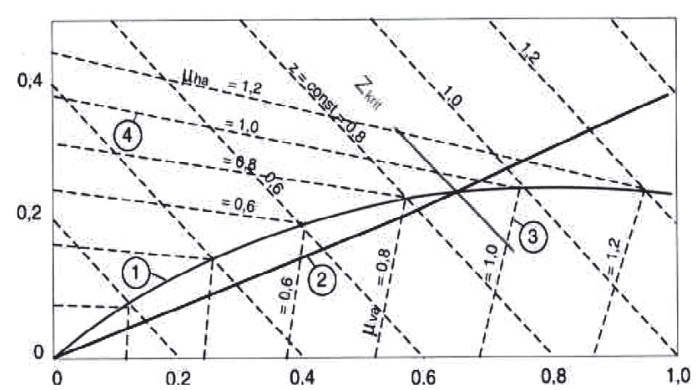

Figura 2. Curva de distribuição de frenagem [1012].

Deste modo, toda condição de projeto que leve o sistema de freio do veículo a operar em qualquer ponto acima da curva de distribuição ideal, conduz ao travamento do eixo traseiro antes do dianteiro, o que pode resultar numa condição de instabilidade de trajetória do veículo durante a frenagem [12]. Já a condição de operação em qualquer ponto abaixo da curva ideal leva ao travamento do eixo dianteiro antes do traseiro, o que é preferível sob o ponto de vista da instabilidade de frenagem.

\section{Análise térmica do sistema de freio a disco}

A temperatura na região de atrito, na interface entre o disco e a pastilha, altera as condições físicas e químicas das superfícies de contato, tornando o desgaste dependente da temperatura dos freios e do atrito no sistema.

Nas superfícies de contato, a geração de calor se comporta de forma não uniforme devido à temperatura pontual ser proporcional à pressão de contato naquele ponto. A pressão de contato sofre as seguintes influências: do desgaste, da geometria 
da pastilha de freio, da posição do pistão de freio em relação à pastilha, das deformações da pastilha e do disco de freio, da temperatura do sistema e da carga imposta a ele [13].

O fluxo de calor é dependente das propriedades físicas e químicas dos materiais da pastilha, do disco de freio e da capacidade do freio de armazenar e dissipar o calor gerado. Esses estão relacionados a volume, massa, densidade e capacidade calorífica dos componentes que constituem este sistema de freio [14].

O suporte metálico, além de resistir à força de frenagem também está exposto a uma parcela do fluxo de calor gerado durante a frenagem [15]. É necessário assim, que o material usado resista às solicitações mecânicas associado a temperatura de serviço. Considerando que o suporte metálico está submetido a um elevado número de ciclos de frenagem (aplicação de carga), o mesmo pode estar sujeito a uma falha por fadiga, contudo, esse trabalho não considera essa hipótese.

Na sequência serão apresentados os recursos usados para a análise do suporte metálico da pastilha de freio, verificando o esforço mecânico aplicado pelo sistema de freio sobre o componente e a temperatura de trabalho ao qual este é submetido durante a sua utilização. A análise destes fatores permitirá determinar a espessura mínima do suporte metálico para atender à solicitação mecânica e à temperatura de trabalho máxima.

\section{MATERIAIS E PROCEDIMENTO}

\section{Sistema de freio e dinamômetro inercial}

O sistema de freio avaliado é da plataforma veicular S4300 usada em carros de passeio e pickups leves. Os materiais dos componentes desse sistema são: suporte metálico (SAE 1020), guarnição de freio e disco de freio e caliper (ferro fundido cinzento).

As características do dinamômetro inercial utilizado para a realização dos ensaios estão apresentadas na Tabela 1.

Os dinamômetros inerciais simulam as condições de um veículo por meio do uso de rodas de inércia conectadas a um eixo. Na ponta do eixo gira o disco
Tabela 1.Características do dinamômetro.

\begin{tabular}{|l|c|c|}
\hline Inércia mínima & $\mathrm{kg} \cdot \mathrm{m}^{2}$ & 5 \\
\hline Inércia máxima & $\mathrm{kg} \cdot \mathrm{m}^{2}$ & 95 \\
\hline Incremento de inércia & $\mathrm{kg} \cdot \mathrm{m}^{2}$ & 1,5 \\
\hline Torque máximo & $\mathrm{N} \cdot \mathrm{m}$ & 3.000 \\
\hline Velocidade máxima & $\mathrm{rpm}$ & 1.500 \\
\hline Carga máxima no eixo & $\mathrm{kg}$ & 2.700 \\
\hline Sistema de atuação & - & Hidráulica \\
\hline
\end{tabular}

de freio, como se fosse no veículo e, acoplado a ele, está o caliper, que é fixo. O caliper de freio está acoplado a uma célula de carga que mede o torque gerado na frenagem, permitindo juntamente com outros parâmetros como pressão e inércias utilizadas, determinar o coeficiente de atrito.

O tipo de ensaio adotado para validação dos resultados é denominado de "ensaio de descida rápida de serra". Nesse ensaio é verificada a resistência estrutural e a capacidade de dissipação de calor do sistema de freio, perda de eficiência do material de atrito, a temperatura do fluido e a capacidade de frenagem do veículo quando o sistema de freio é solicitado em condições severas de uso, simulando um veículo em descida de serra.

O ensaio consiste na simulação de três descidas pelo trajeto, com velocidades iniciais do veículo de respectivamente de 60,70 e $80 \mathrm{~km} / \mathrm{h}$, sendo então realizada a frenagem com o máximo de pressão da linha, obtendo a máxima desaceleração do veículo sem o travamento das rodas até a velocidade atingir $40 \mathrm{~km} / \mathrm{h}$. Retoma-se a velocidade inicial e se repete as condições de frenagem como definido no procedimento de ensaio. O ensaio é realizado em aproximadamente 22, 20 e 18 minutos, respectivamente em relação a velocidade inicial.

Entre as descidas (ensaios), deve-se realizar o processo de recuperação do material de atrito, onde são realizadas 12 aplicações de frenagem com intervalos de $2 \mathrm{~km}$ (monitorada pelo próprio dinamômetro), à velocidade constante de $60 \mathrm{~km} / \mathrm{h}$ em trajeto plano, a fim de verificar a capacidade do material retornar para as condições anteriores ao ensaio no que diz respeito ao seu desempenho de frenagem. 


\section{Procedimento de avaliação de suportes metálicos para sistemas de freio a disco}

Os suportes metálicos são normalmente fabricados em aço, ocorrendo, em algumas aplicações específicas o uso do ferro fundido cinzento. Estes materiais conferem resistência mecânica, rigidez e estabilidade.

Os parâmetros considerados para a avaliação da espessura do suporte metálico são: o torque e a força de frenagem, a temperatura de trabalho, a alteração das propriedades mecânicas do aço devido à elevada temperatura e as possíveis variações dimensionais em função da temperatura e dos esforços. A avaliação foi realizada seguindo as oito etapas apresentadas na Figura 3.

Para a medição da temperatura máxima de trabalho do suporte metálico foram instalados termopares na interface entre a superfície do suporte com a guarnição de freio. A Figura 4 apresenta os pontos onde foram instalados os termopares.

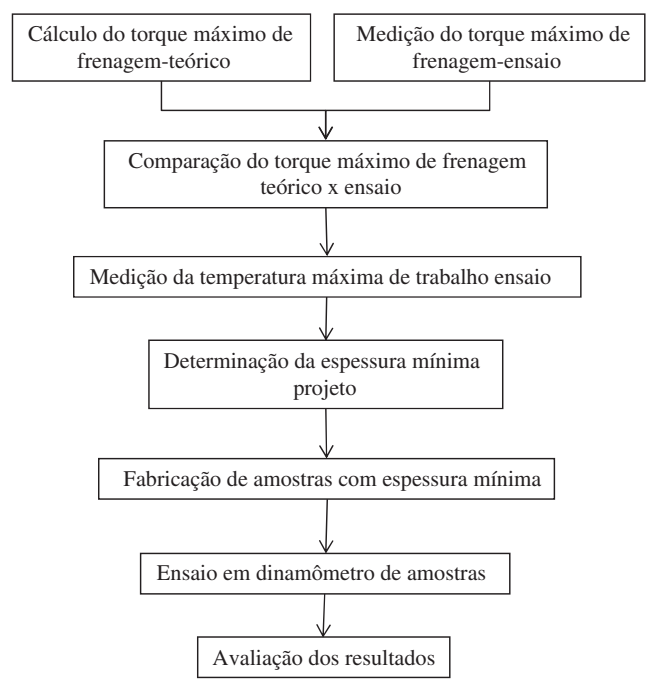

Figura 3. Etapas para avaliação de um suporte metálico de pastilha de freio.

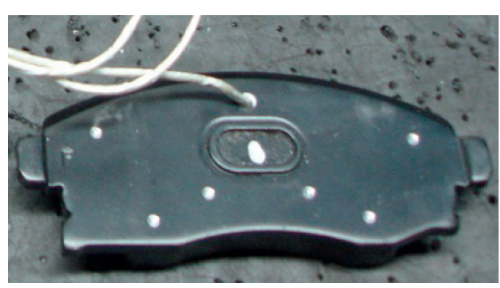

Figura 4. Pontos de medição no suporte metálico.

\section{ETAPAS DE AVALIAÇÃO DO SUPORTE METÁLICO}

\section{Torque máximo de frenagem - teórico}

Para a determinação do torque máximo de frenagem foram consideradas as especificações técnicas do veículo apresentadas na Tabela 2 . O raio de rolamento e o raio efetivo de frenagem foram determinados conforme Reimpell, Stoll e Betzler [12].

Considerando as características do veículo foram calculadas a desaceleração, os pesos distribuídos, $o$ torque de frenagem e o força de frenagem para o eixo dianteiro. A desaceleração é a máxima possível de atingir-se com o atrito de pneu-solo. As relações entre os pesos estáticos e os dinâmicos considerados foram de $70 \%$ do peso do veículo parado no eixo dianteiro e $87 \%$ do peso do veículo em movimento.

Tabela 2.Especificações de projeto.

\begin{tabular}{|l|c|c|}
\hline Massa & $\mathrm{m}$ & $1.900 \mathrm{~kg}$ \\
\hline Altura do centro de gravidade & $\mathrm{H}$ & $0,522 \mathrm{~m}$ \\
\hline Coeficiente de atrito do pneu & $\mu_{\mathrm{HF}}$ & 0,90 \\
\hline $\begin{array}{l}\text { Distância do centro da roda dianteira } \\
\text { ao CG }\end{array}$ & $\mathrm{L}_{\mathrm{d}}$ & $0,815 \mathrm{~m}$ \\
\hline Distância entre os centros das rodas & $\mathrm{L}$ & $2,714 \mathrm{~m}$ \\
\hline $\begin{array}{l}\text { Distância do centro da roda traseira } \\
\text { ao CG }\end{array}$ & $\mathrm{L}_{\mathrm{t}}$ & $1,899 \mathrm{~m}$ \\
\hline Aceleração da gravidade & $\mathrm{g}$ & $9,806 \mathrm{~m} / \mathrm{s}^{2}$ \\
\hline Raio de rolamento & $\mathrm{R}_{\mathrm{r}}$ & $0,281 \mathrm{~m}$ \\
\hline Raio efetivo de frenagem & $\mathrm{R}_{\mathrm{ef}}$ & $0,1087 \mathrm{~m}$ \\
\hline
\end{tabular}

A curva de distribuição de frenagem, Figura 5, apresenta o comportamento do processo de frenagem tanto para o veículo carregado como em vazio.

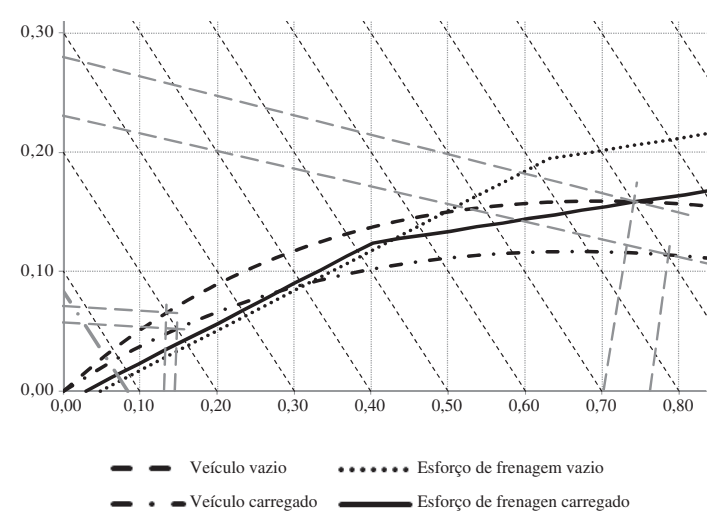

Figura 5. Curva de distribuição de frenagem. 
Assim, é possível visualizar a diferença de forças aplicadas no eixo dianteiro em relação ao eixo traseiro durante o processo de frenagem, sendo que esta diferença aumenta em $24 \%$ quando o veículo selecionado está carregado.

\section{Torque máximo de frenagem - ensaio}

Usando o dinamômetro inercial foi possível obter o torque de frenagem em condições severas de uso, utilizando pastilhas no início e fim de vida útil quando as espessuras do material de atrito são 16,70 mm e 10,00 mm, respectivamente. Na Figura 6, é possível observar o comportamento da configuração no final da vida útil (situação mais crítica). Cada linha do gráfico representa uma diferente condição de ensaio, sendo a $1^{a}$ descida com desaceleração de 60 a $40 \mathrm{~km} / \mathrm{h}$, a $2^{\text {a }}$ descida com desaceleração de 70 a $40 \mathrm{~km} / \mathrm{h}$ e a $3^{\text {a }}$ de 80 a $40 \mathrm{~km} / \mathrm{h}$.

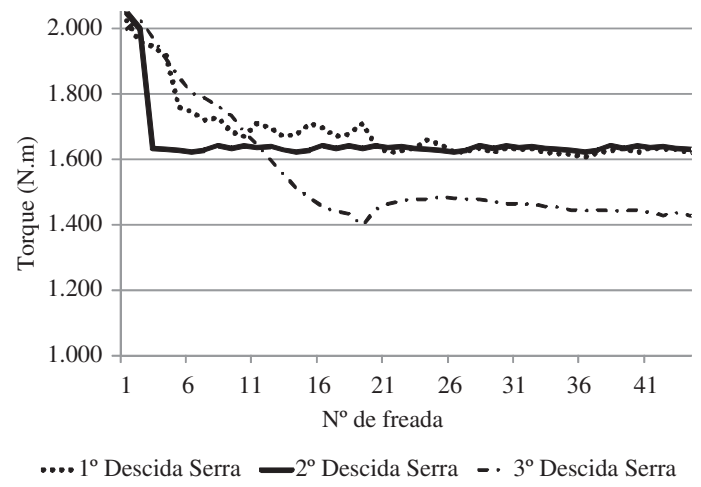

Figura 6. Torque de frenagem no final da vida.

O torque máximo obtido ocorreu no início de cada ensaio, sendo $1.842 \mathrm{Nm}$ para a pastilha em início de vida útil e $2.046 \mathrm{Nm}$ para pastilhas em final de vida útil (Figura 6).

\section{Torque máximo de frenagem: teórico $\mathrm{x}$ ensaio} A partir dos resultados teóricos e daqueles obtidos nos ensaios é possível compará-los. A Tabela 3 apresenta a comparação dos valores de torque e forças de frenagem (Roda Dianteira) entre os cálculos teóricos e valores obtidos em ensaio de laboratório.

A severidade dos ensaios utiliza a máxima especificação do projeto do freio a disco dianteiro com a pastilha em final de vida útil. O torque teórico máximo de projeto foi de 2.057 N.m enquanto o torque medido no ensaio com a pastilha no final da vida útil foi de 2.046 N.m, ou seja, foi atingido
Tabela 3.Projeto versus ensaio.

\begin{tabular}{|l|c|c|}
\hline & $\begin{array}{c}\text { Torque } \\
\text { (N.m) }\end{array}$ & $\begin{array}{c}\text { Força de frenagem - } \\
\text { roda dianteira (N) }\end{array}$ \\
\hline Projeto & 2.057 & 18.923 \\
\hline $\begin{array}{l}\text { Ensaio - pastilha início de } \\
\text { vida }\end{array}$ & 1.842 & 16.946 \\
\hline $\begin{array}{l}\text { Ensaio - pastilha fim de } \\
\text { vida }\end{array}$ & 2.046 & 18.822 \\
\hline
\end{tabular}

99,5\% da especificação do projeto. Estes valores mostram a coerência do projeto em relação ao desempenho exigido pelas normas.

\section{Temperatura máxima de trabalho - ensaio}

As variações da temperatura de frenagem obtidas nos ensaios de descida rápida de serra, no fim de vida útil da pastilha, são mostradas na Figura 7a e 7b.

A temperatura da pastilha em final de vida útil é maior em relação à pastilha em início de vida útil. Isso é explicado pela menor espessura do material de atrito da pastilha que atua neste caso como isolante térmico para o suporte metálico. Pode-se observar que na medida que ocorre a desaceleração existe o aumento da temperatura em todos os pontos (Figura 7 a e 7b). As temperaturas máximas monitoradas nos ensaios com pastilhas em início e final de vida útil são $349^{\circ} \mathrm{C}(7 \mathrm{a})$ e $390^{\circ} \mathrm{C}(7 b)$.

Estes valores de temperatura foram medidos a 21,4mm da região onde o suporte sofre compressão devido ao esforço mecânico. Para a determinação da temperatura na região de compressão do suporte metálico foi necessário realizar uma estimativa teórica admitindo naquela região um processo de transferência de calor uniaxial [16], sendo para isso considerando as características dos materiais da pastilha de freio. Por meio dessa estimativa as temperaturas na região de contato do suporte metálico para as pastilhas em início e fim de vida útil determinadas foram de $157^{\circ} \mathrm{C}$ e $172{ }^{\circ} \mathrm{C}$, respectivamente.

\section{Determinação da espessura mínima de projeto}

A determinação da espessura mínima do suporte foi realizada com base nas especificações do projeto e dos resultados dos ensaios. Inicialmente determinouse o limite de escoamento do material - SAE 1020 - por meio de um ensaio de tração em 6 amostras. O valor médio do limite de escoamento obtido nos ensaios de tração foi de $356,8 \mathrm{MPa}$, com um 
$3^{\circ}$ descida de Serra $80-40 \mathrm{~km} / \mathrm{h} \quad 8,90 \mathrm{~m} / \mathrm{s}^{2}$

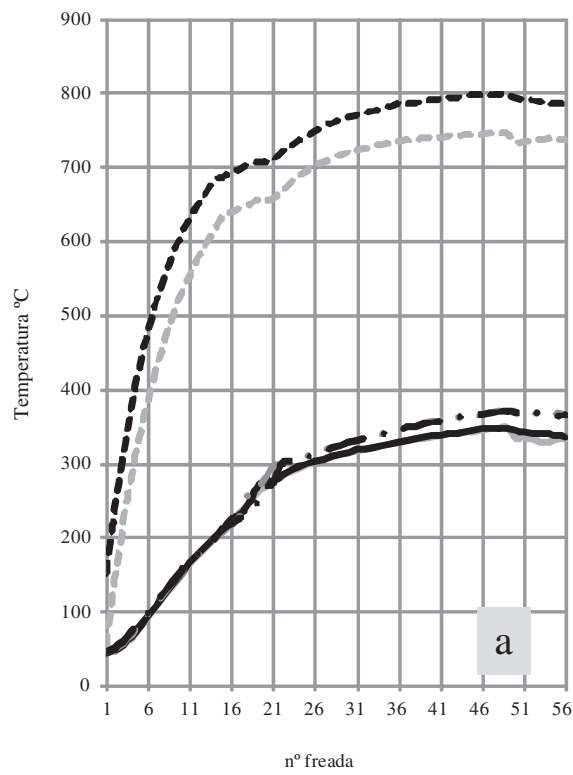

$3^{\circ}$ descida de Serra $80-40 \mathrm{~km} / \mathrm{h} \quad 8,90 \mathrm{~m} / \mathrm{s}^{2}$

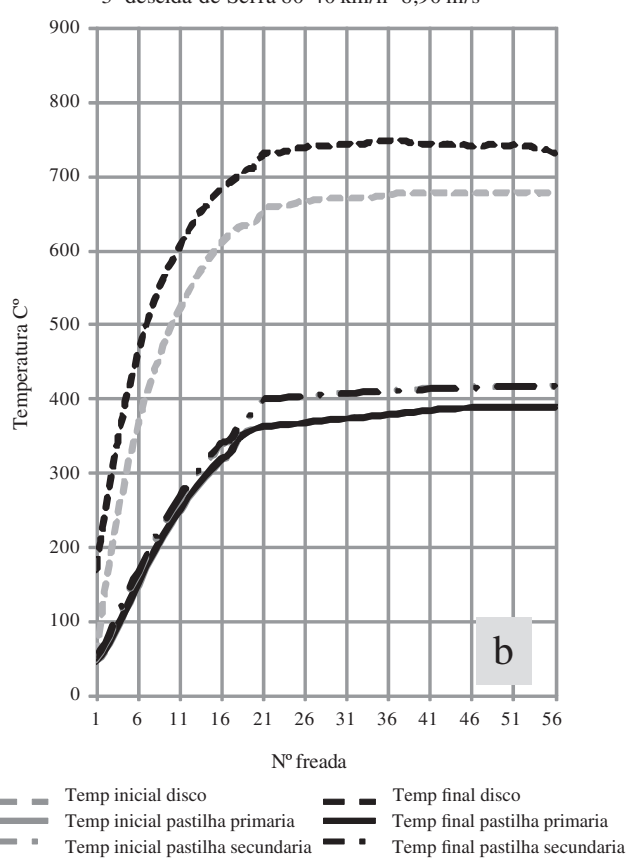

Figura 7. Temperatura de frenagem: pastilha início vida útil (a) final vida útil (b).

desvio padrão de 44,3 $\mathrm{MPa}$. Considerando que a amostragem dos ensaios de tração são pequenas, e assim, não é possível se determinar com acuracidade o valor médio do limite de escoamento optou-se por utilizar o menor limite de escoamento apresentado pelos ensaios de tração, ou seja, $316 \mathrm{MPa}$.
Com base nas especificações do projeto, os resultados obtidos nos ensaios, as propriedades do material e um coeficiente de segurança mínimo de 1,4, conforme norma TS 6-11-101 [17] obteve-se uma espessura mínima para o suporte metálico de $3,65 \mathrm{~mm}$. O valor da espessura mínima foi determinado analíticamente considerando um fator de correção em relação a temperatura atuante no suporte metálico [18]. Tal espessura atende o requisito de $9.461 \mathrm{~N}$ de força de frenagem teórica na pastilha. Considerando-se os padrões comerciais e economicamente disponíveis para utilização na fabricação do suporte, a espessura utilizada para validação desse estudo foi de $4 \mathrm{~mm}$. Assim, o coeficiente de segurança que atualmente é de 1,92 para o suporte metálico de $5 \mathrm{~mm}$ passa a ser de 1,53 para o de $4 \mathrm{~mm}$.

\section{Ensaio em dinamômetro das novas amostras}

As novas pastilhas de freio foram fabricadas com um suporte de $4 \mathrm{~mm}$ de espessura, obtido pela remoção de $1 \mathrm{~mm}$ de material do suporte original, por meio de uma operação de fresamento. Os demais processos de fabricação da pastilha, no caso a moldagem do material de atrito e pintura, foram realizados seguindo os parâmetros de fabricação especificados pela empresa.

Para a validação foram repetidos os ensaios realizados com as pastilhas originais. Contudo foram realizados os ensaios somente com pastilhas em final de vida útil, devido à exigência mecânica e térmica desta configuração ser maior em até $10 \%$ em relação à pastilha em início de vida útil. A Figura 8 mostra os resultados dos dois ensaios realizados para validação das amostras, sendo o torque máximo desenvolvido de $1.968 \mathrm{Nm}$, que representa 95\% do torque especificado no projeto.

É possível observar o aumento do torque entre a vigésima quarta e vigésima quinta frenagem. Isso ocorreu devido à guarnição de freio estar na fase de transição do material de atrito com o material de fundo. O material de fundo é um material que possui o coeficiente de atrito mais elevado que o material de atrito, assim gerando o aumento do torque de frenagem e, está localizado entre o suporte metálico e o material de atrito, propriamente dito.

A Figura 9 apresenta as temperaturas obtidas nos dois ensaios realizados para a pastilha proposta. 


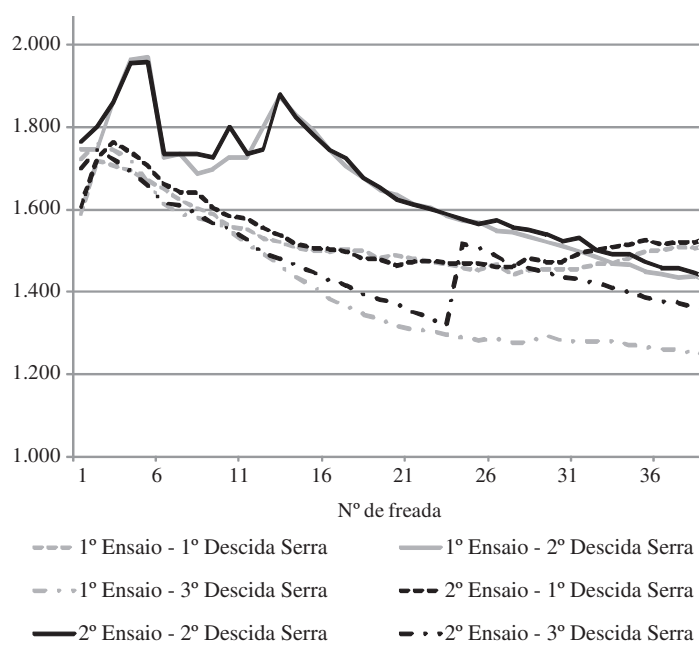

Figura 8. Torque de frenagem obtidos nos ensaios de validação.

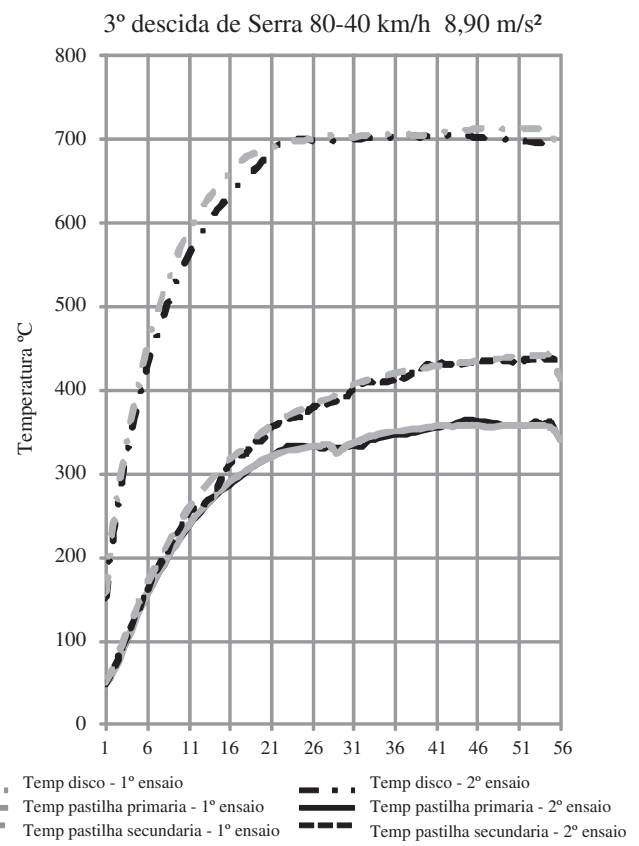

Figura 9. Temperatura de frenagem da pastilha durante ensaios.

As temperaturas máximas monitoradas durante a repetição dos ensaios foram de $358^{\circ} \mathrm{C}$ e $362^{\circ} \mathrm{C}$ nas pastilhas na realização da $3^{\mathrm{a}}$ descida rápida de serra. Entretanto, estas temperaturas foram monitoradas a $19,1 \mathrm{~mm}$ da região aonde a pastilha sofre compressão devido ao esforço mecânico.

Como citado anteriormente, a temperatura na região de compressão do suporte metálico, foi determinada por meio de uma estimativa teórica, admitindo naquela região um processo de transferência de calor uniaxial [16], sendo para isso considerando as características dos materiais. Desta forma, as temperaturas encontradas na região de compressão do suporte metálico são de aproximadamente $168^{\circ} \mathrm{C}$ e $170{ }^{\circ} \mathrm{C}$, respectivamente.

\section{ANÁLISE DOS RESULTADOS}

\section{Torque de frenagem}

O torque de frenagem é uns dos principais itens que devem ser analisados, visto que a partir dele é possível se determinar a força de frenagem, e assim determinar a carga de compressão que o suporte metálico está sendo submetido. Para realizar os comparativos de torque entre ambas as configurações (original e nova proposta) de suporte metálico, os resultados obtidos nos ensaios foram divididos entre as 3 descidas de serra. A Figura 10 apresenta o resultado dos carregamentos aplicados nos ensaios em ambas as configurações do suporte metálico para a $2^{\mathrm{a}}$ descida de serra realizada.

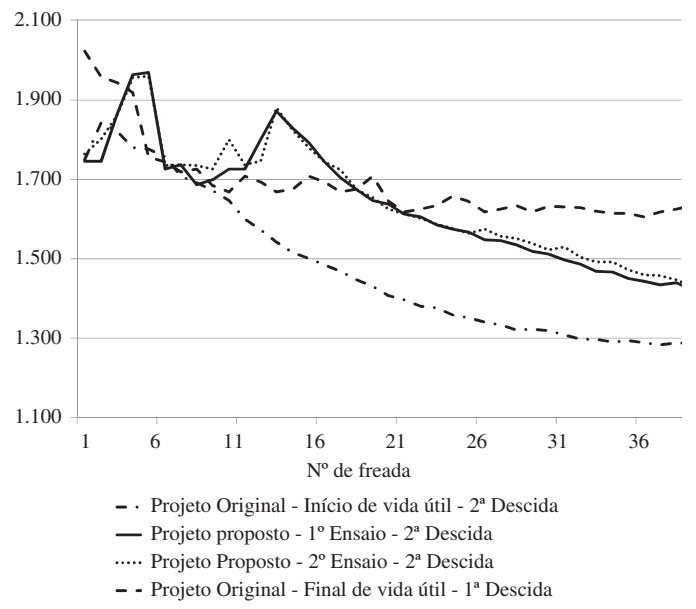

Figura 10. Comparativo do torque de frenagem aplicado na $2^{\text {a }}$ descida de serra.

A Figura 11 apresenta o resultado dos carregamentos aplicados nos ensaios em ambas as configurações do suporte metálico para a $3^{\mathrm{a}}$ descida de serra realizada.

Analisando as Figuras 10 e 11, pode-se observar que o torque de frenagem aplicado em ambas as configurações de suporte metálico são similares. Porém é possível perceber nas 20 primeiras frenagens a ocorrência de oscilações nos resultados do torque 


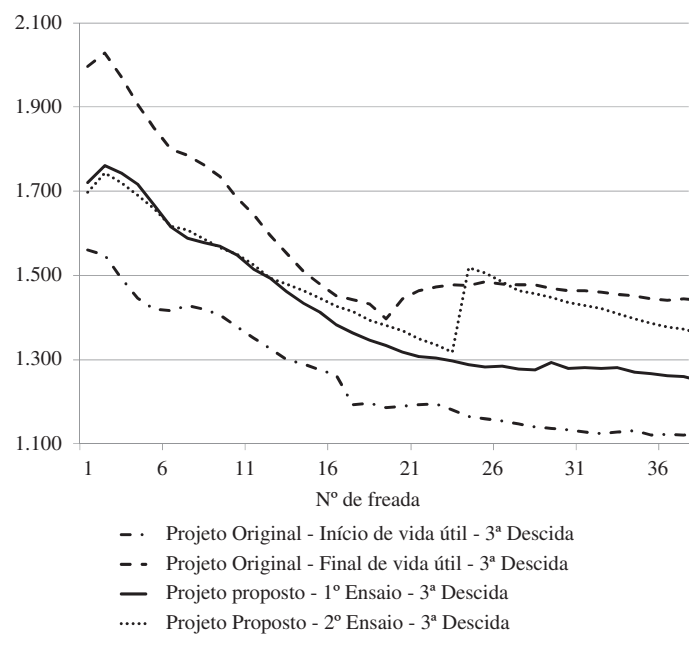

Figura 11. Comparativo do torque de frenagem aplicado na $3^{\text {a }}$ descida de serra.

entre as frenagens. Este fato ocorre devido à perda do coeficiente de atrito entre as frenagens, que ocorre em função do aumento da temperatura na interface disco e pastilha. Na medida em que ocorre a estabilização da temperatura na interface, ocorre também a estabilização do torque de frenagem.

Na Figura 11 pode-se observar na vigésima quinta frenagem a ocorrência do aumento do torque e, isto ocorreu devido a guarnição de freio estar na fase de transição do material de atrito com o material de fundo. Este material de fundo possui o coeficiente de atrito mais elevado que o material de atrito.

\section{Temperatura do suporte metálico}

$\mathrm{O}$ aumento da temperatura no sistema de freio se deve pela transformação da energia cinética em calor interferindo no coeficiente de atrito do material e influenciando diretamente na resistência e rigidez do suporte metálico.

O monitoramento da temperatura obtida nos ensaios é apresentado na Figura 12, que ilustra a temperatura da " 3 a descida de serra" de cada ensaio, porque este representa a mais severa dentre todos os ensaios.

Como pode ser observado na Figura 12, entre os ensaios realizados as temperaturas monitoradas no disco são similares. Esta ocorrência também pode ser observada nas temperaturas monitoradas no suporte metálico. Contudo a diferença da temperatura entre disco e suporte metálico é de aproximadamente de $350^{\circ} \mathrm{C}$, com exceção da pastilha em início de vida útil, aonde a diferença chega atingir a $420^{\circ} \mathrm{C}$. Esta diferença maior ocorre devido à espessura do material de atrito ser maior, agindo assim como isolante térmico.

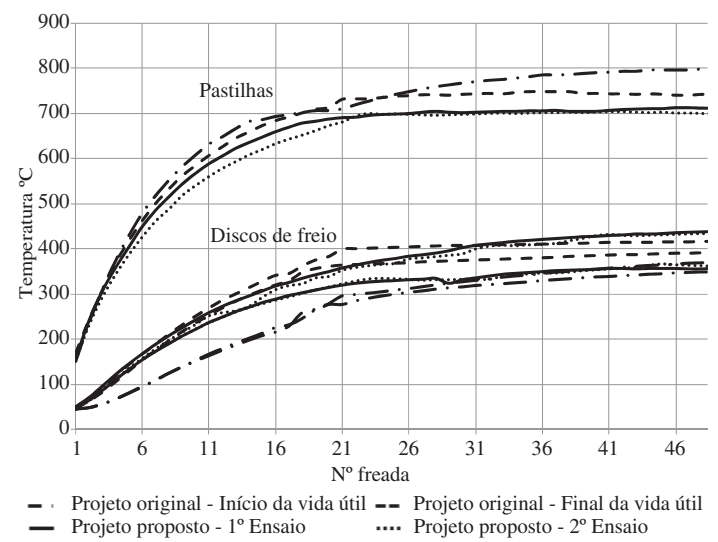

Figura 12. Comparativo das temperaturas obtidas nos ensaios.

Pode-se observar nas primeiras 20 frenagens, que a taxa de aumento da temperatura é elevada em relação às frenagens posteriores, onde a partir deste ponto ocorre a redução da taxa de crescimento desta até que a mesma se estabilize. A partir da estabilização da temperatura é possível determinar seus valores nas regiões de apoio do suporte metálico, sendo assim, onde o valor monitorado foi de $362{ }^{\circ} \mathrm{C}$ e a respectiva temperatura para a região de apoio do suporte foi estimada em $170{ }^{\circ} \mathrm{C}$, admitindo naquela região um processo de transferência de calor uniaxial.

\section{CONCLUSÕES}

Este trabalho avaliou a redução da espessura do suporte metálico da pastilha de freio, e sua influência no desempenho de frenagem de veículos leves.

Considerando um veículo comercial, foram determinadas as forças atuantes durante a frenagem e validadas com os ensaios de simulação. Durante o ensaio foi evidenciado que o torque desenvolvido representa $99,4 \%$ do torque calculado no projeto. Este ensaio possibilitou avaliar as principais dimensões do suporte metálico e monitorar a temperatura à qual ele é submetido durante a aplicação.

Conhecida a temperatura máxima atingida no suporte metálico e o ponto onde esta foi monitorada, 
determinou-se a temperatura na região de apoio do suporte, que sofre a compressão junto ao caliper, considerando uma transferência de calor uniaxial. Considerando que o suporte metálico está submetido a um valor de temperatura superior a temperatura ambiente, foi necessário aplicar um coeficiente de correção do limite de escoamento do material para compensar a variação de temperatura, conforme sugerido por Souza [18].

Para a determinação da espessura mínima do suporte foi usado como parâmetro de projeto o valor do limite de escoamento do material. Para a obtenção desse dado foram realizados dois métodos. O primeiro consistiu na realização de ensaios de tração onde se obteve o valor de $316 \mathrm{MPa}$, o qual foi adotado no dimensionamento. O segundo método consistiu em determinar o valor do limite de escoamento por meio da dureza na superfície da peça, obtida por ensaios de micro dureza. Esse método apresentou um valor elevado em função do processo de estampagem a que é submetido o suporte, sendo, portanto desconsiderado por não representar de forma adequada o valor do limite de escoamento do material.

A espessura mínima do suporte foi determinada com o coeficiente de segurança 1,4 conforme normas de especificação técnica. Associado a isso foi considerado o fator de correção do limite de escoamento em função da temperatura. A espessura mínima determinada foi de $3,65 \mathrm{~mm}$, porém esta espessura não é padrão de fabricação sendo adotado, neste caso, $4 \mathrm{~mm}$.

Os novos suportes, quando submetidos à repetição dos ensaios de simulação de descida rápida de serra, apresentaram resultados similares de torque e temperatura quando comparados com os primeiros ensaios realizados. Sendo assim, a utilização do suporte metálico com a espessura proposta é viável utilizando estes critérios de avaliação.

\section{REFERÊNCIAS}

[1] R.G. Lamb. "Estudo do comportamento de desgaste de materiais de atrito em função de variáveis de aplicação". Dissertação (Mestrado em Materiais). Universidade de Caxias do Sul. Caxias do Sul, Brasil. 2008.
[2] O. Maluf, M. Angeloni, J.C. Santos, M.A. Colósio, D. Spinelli e W. Bose F. "Desenvolvimento Histórico e tecnológico dos Discos de Freio Automotivos". SAE Technical Paper 7TH International brake Colloquium Caxias do Sul, Brasil. 2005.

[3] J.P. Pompon. "The brake disc manual". Publicações Brembo SpA. 1997.

[4] L.T. Matozo. "Análise de materiais de fundo de alto amortecimento e de seus efeitos em pastilhas de freio". Dissertação (Mestrado em Engenharia). Universidade Federal do Rio Grande do Sul. Porto Alegre, Brasil. 2006.

[5] O.M. Madureira. "Dinâmica de Veículos: Apresentação e discussão dos fatos básicos". EP-USP. São Paulo, Brasil. 2004.

[6] G.J. Gardinalli. "Comparação do desempenho de frenagem simulada x experimental de um veículo de passeio com freios hidráulicos e ABS. Dissertação (Mestrado em Engenharia Automotiva). Universidade de São Paulo. São Paulo, Brasil. 2005.

[7] ABNT NBR 14353: "Veículos Rodoviários - Veículos motorizados equipados com sistema antibloqueio de frenagem - Medida do desempenho do freio". Rio de Janeiro, Brasil. 1999.

[8] R. Limpert. "Brake design and safety". Second edition. SAE. USA. 1999.

[9] H. Kawagushi. "Comparação da análise de conforto de frenagem subjetiva x objetiva de um veículo de passeio". Dissertação (Mestrado em Engenharia Automotiva). Escola Politécnica da Universidade de São Paulo. São Paulo, Brasil. 2005.

[10] P. Rieth, S. Drumm und M. Harnischfeger. "Elektronisches Stabilitätsprogramm". s.L.: Verlag Moderne Industrie, p. 223. Bibliothek der Technik. Germany. 2001.

[11] G.J. Gardinalli. Comparação do desempenho de frenagem simulada $x$ experimental de um veículo de passeio com freios hidráulicos e ABS. Dissertação (Mestrado em Engenharia Automotiva). Escola Politécnica da Universidade de São Paulo. São Paulo, Brasil. 2005.

[12] J. Reimpell, H. Stoll and J.W. Betzler. Braking behavior. "The Automotive Chassis: Engineering Principles". Second edition. Warrendale: Society of Automotive Engineers, Inc. 2001. 
[13] W. Rumold and R.A. Swift. "Evaluation of disc brake pad pressure distribution by multibody dynamic analysis". International Conference Braking 2002 - From the driver to the road. SAE. 2002.

[14] S. Eppler, T. Klnk and J. Wiedemann. "Thermal simulation within the brake system design process". SAE. Paper $\mathrm{N}^{\circ}$ 2002-012587. 2002. DOI: 10.4271/2002-01-2587.

[15] A. Brezolin. "Estudo de geração de trincas térmicas em discos de freios de veículos comerciais". Dissertação (Mestrado em
Materiais). Universidade de Caxias do Sul. Caxias do Sul, Brasil. 2007.

[16] F.P. Incropera e D.P. Dewitt. "Fundamentos de transferência de calor e de massa". Fifth edition. LTC. Rio de Janeiro, Brasil. 2003.

[17] Lucas. "Technical Specification". Lucas Automotive GmbH. 1995.

[18] V. Souza. "Simulação computacional do comportamento de estruturas de aço sob incêndio". Tese (Doutorado em Engenharia Civil). Universidade Federal do Rio Grande do Sul. Porto Alegre, Brasil. 2004. 